\title{
Effect of rosuvastatin on diabetic polyneuropathy: a randomized, double-blind, placebo-controlled Phase lla study
}

This article was published in the following Dove Press journal:

Diabetes, Metabolic Syndrome and Obesity: Targets and Therapy

4 September 2014

Number of times this article has been viewed

\author{
Jaime Hernández-Ojeda \\ Luis Miguel Román-Pintos \\ Adolfo Daniel Rodríguez- \\ Carrízalez \\ Rogelio Troyo-Sanromán \\ Ernesto Germán Cardona- \\ Muñoz \\ María del Pilar Alatorre-

\section{Carranza} \\ Alejandra Guillermina \\ Miranda-Díaz \\ Departamento de Fisiología, \\ Centro Universitario de Ciencias \\ de la Salud, Universidad de \\ Guadalajara, Jalisco, México
}

Correspondence: Alejandra Guillermina Miranda-Díaz

Instituto de Terapéutica Experimental y Clínica, Centro Universitario de Ciencias de la Salud, Universidad de Guadalajara, Av La Paz No 2758, Col Arcos Sur, CP 44I50, Guadalajara, Jalisco, México Tel +52 $33 \quad 0585200$ ext 33658 Fax +523336173499

Email kindalexI@outlook.com
Background: Diabetic neuropathy affects $50 \%-66 \%$ of patients with diabetes mellitus. Oxidative stress generates nerve dysfunction by causing segmental demyelinization and axonal degeneration. Antioxidants are considered to be the only etiologic management for diabetic polyneuropathy, and statins such as rosuvastatin increase nitric oxide bioavailability and reduce lipid peroxidation. The aim of this study was to evaluate the antioxidant effect of rosuvastatin in diabetic polyneuropathy.

Methods: We conducted a randomized, double-blind, placebo-controlled Phase IIa clinical trial in patients with type 2 diabetes and diabetic polyneuropathy (DPN) stage $\geq 1 \mathrm{~b}$. We allocated subjects to two parallel groups (1:1) that received rosuvastatin $20 \mathrm{mg}$ or placebo for 12 weeks. Primary outcomes were neuropathic symptom score, disability score, and nerve conduction studies, and secondary outcomes were glycemic control, lipid and hepatic profile, lipid peroxidation, and nerve growth factor beta (NGF- $\beta$ ) levels.

Results: Both groups were of similar age and duration since diagnosis of diabetes and DPN. We observed improvement of DPN in the rosuvastatin group from stage $2 \mathrm{a}(88.2 \%)$ to stage $1 \mathrm{~b}$ (41.2\%), improvement of neuropathic symptom score from $4.5 \pm 2$ to $2.4 \pm 1.8$, and significant ( $P=0.001$ ) reductions of peroneal nerve conduction velocity (from $40.8 \pm 2.2$ to $42.1 \pm 1.6$ seconds) and lipid peroxidation (from $25.4 \pm 2$ to $12.2 \pm 4.0 \mathrm{nmol} / \mathrm{mL}$ ), with no significant change in glycemic control or $\beta$-NGF.

Conclusion: The severity, symptoms, and nerve conduction parameters of DPN improved after 12 weeks of treatment with rosuvastatin. These beneficial effects appear to be attributable to reductions in lipid peroxidation and oxidative stress.

Keywords: rosuvastatin, diabetic polyneuropathy, nerve conduction, oxidative stress, nerve growth factor beta

\section{Introduction}

According to the World Health Organization, approximately 346 million people worldwide have diabetes mellitus (DM). ${ }^{1}$ Diabetic polyneuropathy (DPN) is a heterogeneous disease that involves various parts of the nervous system and produces a variety of clinical symptoms. ${ }^{2} \mathrm{DPN}$ is the most common complication of $\mathrm{DM}^{3}$ and its prevalence ranges between $50 \%$ to $66 \%$ in patients with the disease. ${ }^{4} \mathrm{~A}$ composite score has been developed to diagnose DPN, based on clinical manifestations and nerve conduction studies. The neuropathic symptom score (NSS) and neuropathic impairment score (NIS) collect a series of neurological data used for the clinical diagnosis, and a score $\geq 2$ is considered positive for DPN. ${ }^{5}$ Nerve conduction studies involve electrical stimulation of a peripheral nerve and the neuromuscular junction to evaluate nerve latency, 
amplitude, and velocity, ${ }^{6}$ and a test is deemed to be positive if there is a difference of two or more standard deviations in two distinct parameters observed in two or more nerves. ${ }^{7}$

Hyperglycemia damages cells by increasing oxidative stress through formation of advanced glycation end-products, which are responsible for covalent attachment to proteins and structural changes in nerve cells. ${ }^{8,9}$ Hyperglycemia also affects nerve conduction via axonal degeneration and segmental demyelinization, leading to loss of functional myelin nerve fibers. ${ }^{10,11}$ Another physiopathologic pathway leading to nerve dysfunction consists of alterations in synthesis and/or expression of neurotropic factors, such as nerve growth factor beta (NGF- $\beta$ ) and tissue growth factor $1 .{ }^{12}$

Use of antioxidants in DM is controversial, but could be considered because they may be effective in reducing the risk of developing microvascular complications. ${ }^{13}$ Antioxidants can counteract the effects of reactive oxygen species and lipid peroxides (LPO), thereby restoring the balance between the processes of myelinization and demyelinization induced by oxidative stress. ${ }^{14}$ Rosuvastatin decreases cholesterol levels by inhibiting hydroxymethylglutaryl-coenzyme A reductase; however, some pleiotropic effects have been proposed, including improvement of endothelial function, increased bioavailability of nitric oxide, ${ }^{15}$ stabilization of atherosclerotic plaque and as a potent systemic antioxidant. ${ }^{16,17}$ Statins also reduce reactive oxygen species via vascular nicotinamide adenine dinucleotide phosphate oxidase and antagonize the prooxidant effects of angiotensin II and endothelin- $1 .{ }^{18}$ Further, rosuvastatin reduces oxidation of low-density lipoprotein. ${ }^{19,20}$ Therefore, we evaluated the effects of rosuvastatin in patients with DPN.

\section{Patients and methods Study design and population}

We performed a randomized, double-blind, placebocontrolled, parallel-group, Phase IIa clinical trial with an allocation ratio of $1: 1$. We selected patients who lived in Guadalajara or its surrounding areas from primary care clinics, by invitation via public forums for patients with DM, and telephone calls to patients in the database held by our research unit. Management of glycemia and blood pressure was left to their usual physicians, and adjustments to this regard were made based on clinical guidelines during the study. Male and female patients with type $2 \mathrm{DM}$ were eligible for inclusion if they were aged 35-80 years, had a glycated hemoglobin level $<12 \%$ and DPN stage $\leq 2 \mathrm{~b}$, and were able to provide signed informed consent. We excluded patients with other types of neuropathy (alcohol, autoimmune, hereditary, inflammatory, drug-induced, vitamin deficiency-related); pregnant and nursing women; those who had used antioxidant therapy in the 3 months before randomization; those who had previously been treated with a statin or those who strictly required immediate statin use; and those who could not understand instructions due to educational or physical limitations. Patients could withdraw from the study at any time if they wished and were removed if any severe adverse reaction or critical illness occurred.

Primary outcomes were regression of clinical DPN stage and improvement in NSS, NIS, and nerve conduction studies. The investigator responsible for giving the bottle of study medication to the study patients was trained by a neurologist to obtain information through anamnesis and physical examination for calculation of the aforementioned scores according to Dyck et al. ${ }^{5}$ Nerve conduction studies were performed according to American Association of Electrodiagnostic Medicine guidelines, ${ }^{21}$ recording latency, duration, amplitude, and motor nerve conduction velocity from the fibular, tibial, median, and ulnar nerves, and sensitivity parameters from the sural, median, and ulnar nerves. Secondary outcomes were changes in LPO and $\beta$-NGF.

The sample size was calculated based on peroneal nerve conduction velocity for DPN stage $1 \mathrm{~b}(41 \pm 3 \mathrm{~m} / \mathrm{sec})$, with a difference of $3 \mathrm{~m} / \mathrm{sec}$ for the experimental group, a confidence interval of $95 \%$, and power of $80 \%$. A coinvestigator randomized patients in two-member blocks to rosuvastatin 20 mg or placebo using a computer-generated list previously established by a statistician. The study medications were matched for color, taste, and size by a pharmacist, and sealed in dark containers each containing 30 pills. Another researcher handed each bottle of study medication to the patient and instructed them to take their allocated medication once a day before their evening meal. To ensure adherence, each subject was required to write down the time and date they took the medication, and was instructed not to double any doses. Patients were also asked to describe any adverse events in the same diary. We scheduled one visit per month until completion of the study, at which time we performed a pill count, reviewed their diary, and recorded any adverse events potentially related to the study drug. Patients, their health care providers, and all the study investigators were blinded.

\section{Lipid peroxidation products}

Serum LPO levels were measured using an FR12 ${ }^{\circledR}$ assay kit (Oxford Biomedical Research Inc., Oxford, MI, USA) according to the manufacturer's instructions. In this assay, 
the chromogen reagent reacts with malondialdehyde and 4-hydroxyalkenals to form a stable chromophore. First, $200 \mu \mathrm{L}$ of serum with $455 \mu \mathrm{L}$ of N-methyl-2-phenylindole in acetonitrile (reagent 1) was diluted with ferric acid in methanol. Samples were agitated, after which $105 \mu \mathrm{L}$ of methanesulfonic acid was added, followed by incubation at $45^{\circ} \mathrm{C}$ for 60 minutes and centrifugation at $12,791 \mathrm{rpm}$ for 10 minutes. Next, $200 \mu \mathrm{L}$ of the supernatant was added and absorbance was measured at $586 \mathrm{~nm}$. The standard curve pattern with known concentrations of 1,1,3,3-tetramethoxypropane in Tris- $\mathrm{HCl}$ was used.

$\beta$-NGF levels were determined by enzyme-linked immunosorbent assay (DY256 kit, R\&D Systems, Inc., Minneapolis, MN, USA ). First, $100 \mu \mathrm{L}$ of serum was added to the antibody, which was diluted to $2 \mu \mathrm{g} / \mathrm{mL}$ phosphate-buffered saline. After several steps, comprising addition of reactants, several washing and incubating periods, a $2 \mathrm{~N} \mathrm{H}_{2} \mathrm{SO}_{4}$ solution was added to stop the reaction. Finally, the plate was read at a wavelength of $450 \mathrm{~nm}$ and reported in $\mathrm{pg} / \mathrm{mL}$.

\section{Statistical analysis}

The results for quantitative variables are expressed as the mean \pm standard deviation. The Mann-Whitney $U$ test was used for between-group analysis, and Wilcoxon tests were used for values recorded before and after treatment. Qualitative parameters are reported as percentages, using the chi-squared or Fisher's Exact test for intergroup and intragroup analysis. A $P$-value $\leq 0.05$ was considered to be statistically significant, with a confidence interval of $95 \%$.

\section{Ethical considerations}

The study was performed in accordance with the updated Declaration of Helsinki (2000) and in agreement with local and national laws. Coded numbers were assigned to ensure patient confidentiality. The protocol and procedures for informed consent were reviewed and approved by the ethics and research committee at Centro Universitario de Ciencias de la Salud de la Universidad de Guadalajara. The study is registered at clinicaltrials.gov (NCT01622777).

\section{Results}

There were no statistically significant differences in demographic characteristics between the two groups at baseline. The mean patient age in the rosuvastatin group was $57.6 \pm 7$ years versus $57 \pm 10$ years in the controls $(P=0.809)$. The majority of the study participants were women $(82.4 \%$ in the rosuvastatin group versus $88.2 \%$ in the control group; $P=0.628$ ). Time since diagnosis of type $2 \mathrm{DM}$ in the rosuvastatin group was $9.7 \pm 6.3$ years versus $8.1 \pm 5.6$ years in the control group $(P=0.325)$. Time since diagnosis of DPN was $19.3 \pm 18.4$ months in the rosuvastatin group versus $18.8 \pm 14.1$ months in the control group $(P=0.727)$. Treatment for diabetes was not modified during the study period, and the responsibility for glycemic control remained with the family physician. In the rosuvastatin group, 5.9\% were managed with glyburide, $41.2 \%$ with metformin/glyburide, $5.9 \%$ with insulin, and $47.1 \%$ with a combination of insulin and oral antidiabetic agents. In the control group, $35.3 \%$ were treated with glyburide, $11.8 \%$ with metformin, $29.4 \%$ with metformin/glyburide, $5.9 \%$ with insulin, and $17.6 \%$ with insulin/oral antidiabetic agents $(P=0.085)$. Descriptive analysis showed that most patients in the rosuvastatin group and most of those in the control group had sensorimotor neuropathy (88.2\% and $94.1 \%$, respectively; Table 1$)$.

\section{Clinical evaluation}

At baseline, $88.2 \%$ of patients in the rosuvastatin group had DPN stage $2 \mathrm{a}$ and $11.8 \%$ had stage $2 \mathrm{~b}$. At the end of treatment, $41.2 \%$ of patients were at stage $1 \mathrm{~b}, 52.9 \%$ had stage $2 \mathrm{a}$, and $5.9 \%$ had stage $2 \mathrm{~b}(P=0.030)$. In the control group, $64.7 \%$ had DPN stage $2 \mathrm{a}$ and $35.3 \%$ had stage $2 \mathrm{~b}$ at baseline; after intervention, $11.8 \%$ had stage $1 \mathrm{~b}, 70.6 \%$ had stage $2 \mathrm{a}$, and $17.6 \%$ had $2 \mathrm{~b}$, with no significant difference before and after treatment $(P=0.122)$. NSS was reduced by half in the study and control groups, with no statistically significant between-group differences $(4.5 \pm 2$ at baseline versus $2.4 \pm 1.8$ at the final observation for the rosuvastatin group and $4.4 \pm 1$ versus $2.4 \pm 1.5$, respectively, for the control

Table I Treatment of diabetes mellitus

\begin{tabular}{llllll}
\hline & $\begin{array}{l}\text { Rosuvastatin } \\
(\mathbf{n}=17)\end{array}$ & $\begin{array}{l}\text { Placebo } \\
(\mathbf{n}=17)\end{array}$ & $P$-value \\
\hline Sex & 3 & $17.6 \%$ & 2 & $11.8 \%$ & 0.628 \\
$\quad$ Male & 14 & $82.4 \%$ & 15 & $88.2 \%$ & \\
$\quad \begin{array}{l}\text { Female } \\
\text { Diabetes treatment }\end{array}$ & & & & & \\
$\quad$ Glyburide & 1 & $5.9 \%$ & 6 & $35.3 \%$ & 0.085 \\
$\quad \begin{array}{l}\text { Metformin } \\
\text { Glyburide + metformin }\end{array}$ & 0 & $0.0 \%$ & 2 & $11.8 \%$ & \\
$\quad$ Insulin & 1 & $41.2 \%$ & 5 & $29.4 \%$ & \\
$\quad$ Insulin + other oral & 8 & $47.9 \%$ & 1 & $5.9 \%$ & \\
$\quad$ antidiabetic agents & & & 3 & $17.6 \%$ & \\
Symptomatic treatment & & & & & \\
$\quad \begin{array}{l}\text { Anti-inflammatory drugs } \\
\text { None }\end{array}$ & 0 & $0.0 \%$ & 2 & $11.8 \%$ & 0.15 \\
\hline
\end{tabular}

Notes: More women than men were included in the study; $47.1 \%$ of patients were managed with insulin and oral hypoglycemic agents, followed by glyburide + metformin. The selection of patients in both groups showed homogeneity. 
group). The baseline NIS was $7.4 \pm 2.1$ and after treatment was $7.5 \pm 4.6$ in the rosuvastatin group, with respective values of $8.3 \pm 4.9$ and $8.4 \pm 4.7$ in the control group, and no significant between-group or pre-post treatment differences (Table 2).

Nerve conduction studies were similar in both groups at baseline, with improvement of peroneal nerve conduction at the end of treatment in the rosuvastatin group $(P<0.038)$. A slight (albeit not statistically significant) improvement was also seen in median nerve conduction velocity and popliteal amplitude. There were no differences in the controls before and after treatment (Table 3).

\section{Lipid peroxidation and nerve growth factor beta levels}

The baseline serum LPO level was $25.4 \pm 2 \mathrm{nmol} / \mathrm{mL}$ in the rosuvastatin group and $17.6 \pm 14.5 \mathrm{nmol} / \mathrm{mL}$ in the control group $(P=0.13)$, and mean levels were $12.2 \pm 4.0 \mathrm{nmol} / \mathrm{L}$ and $26.6 \pm 3.6 \mathrm{nmol} / \mathrm{mL}$, respectively, after treatment, with a significant $(P=0.001)$ reduction in the rosuvastatin group. The mean baseline $\beta$-NGF level was $64.4 \pm 22.6 \mathrm{pg} / \mathrm{mL}$ in the rosuvastatin group and $65.8 \pm 16.5 \mathrm{pg} / \mathrm{mL}$ in the control group, and was unchanged after intervention $(66.8 \pm 25.4 \mathrm{pg} / \mathrm{mL}$ on rosuvastatin versus $66.5 \pm 26.7 \mathrm{pg} / \mathrm{mL}$ for controls; $P=0.9$ ).

\section{Metabolic parameters}

Patients were hyperglycemic at baseline and at the end of treatment in both groups. Mean fasting glucose was $193.1 \pm 80.1$ $\mathrm{mg} / \mathrm{dL}$ at baseline and $199.3 \pm 85.5 \mathrm{mg} / \mathrm{dL}$ at the end of the study in the rosuvastatin group $(P=0.2)$, and was $192.5 \pm 83.2$ $\mathrm{mg} / \mathrm{dL}$ at baseline versus $220.1 \pm 83.2 \mathrm{mg} / \mathrm{dL}$ at the end $(P=0.9)$ in controls. Glycated hemoglobin in the rosuvastatin group

Table 2 Stage, type, and degree of diabetic neuropathy

\begin{tabular}{|c|c|c|c|c|c|c|}
\hline & \multicolumn{2}{|c|}{$\begin{array}{l}\text { Rosuvastatin } \\
(n=I 7)(\%)\end{array}$} & \multirow[t]{2}{*}{$P$-value } & \multicolumn{2}{|c|}{$\begin{array}{l}\text { Placebo } \\
(n=\mid 7)(\%)\end{array}$} & \multirow[t]{2}{*}{$P$-value } \\
\hline & Baseline & Final & & Baseline & Final & \\
\hline \multicolumn{7}{|l|}{ Stage } \\
\hline $\mathrm{Ib}$ & 0.0 & 41.2 & 0.03 & 0.0 & 11.8 & 0.2 \\
\hline $2 a$ & 88.2 & 52.9 & & 64.7 & 70.6 & \\
\hline $2 b$ & 11.8 & 5.9 & & 35.3 & 17.6 & \\
\hline \multicolumn{7}{|l|}{ Type } \\
\hline Motor & 11.8 & 23.5 & 0.1 & 5.9 & 17.6 & 0.3 \\
\hline Sensory & 0.0 & 0.0 & & 0.0 & 0.0 & \\
\hline Mixed & 88.2 & 76.5 & & 94.1 & 83.4 & \\
\hline \multicolumn{7}{|l|}{ Degree } \\
\hline Mild & 52.9 & 70.6 & 0.04 & 64.7 & 70.6 & 0.7 \\
\hline Moderate & 41.2 & 17.6 & & 29.4 & 23.5 & \\
\hline Severe & 5.9 & 11.8 & & 5.9 & 5.9 & \\
\hline
\end{tabular}

Notes: Patients with diabetic neuropathy treated with rosuvastatin showed a significant improvement in stage and degree of diabetic neuropathy; in the placebo group, there was no significant change in stage, type, or degree of diabetic neuropathy. The values in bold are statistically significant. was $8.8 \% \pm 2.4 \%$ at baseline and $9.4 \% \pm 1.5 \%$ after treatment $(P=0.2)$; respective mean values in the placebo group were $9.3 \% \pm 2.8 \%$ and $9.9 \% \pm 2.5 \%(P=0.8)$.

As expected, there was a significant reduction in lipid parameters after treatment in the rosuvastatin group but not in the control group. Transaminases and bilirubin remained unchanged in both groups before and after intervention. No drug adverse reactions were reported (Table 4).

\section{Discussion}

The importance of estimating the severity of DPN according to nerve conduction studies and neurologic findings was exposed in the joint meeting of the 19th annual Diabetic Neuropathy Study group of the European Association for the study of Diabetes (NEURODIAB) and the 8th International Symposium on Diabetic Neuropathy in Toronto, Canada, October 13-18, 2009. The reason for this approach lies in the existence of subclinical DPN and difficulties in quantifying neuropathic symptoms despite standardized questionnaires developed for this purpose. ${ }^{22}$ Recently, an association between use of statins and peripheral neuropathy has been suggested; however, the evidence for this relationship comes from crosssectional studies which are susceptible to multiple biases, nerve conduction studies were not analyzed, and no subclassification for specific statins has been reported..$^{23,24}$ On the other hand, a retrospective cohort from 2004-2008 reported a significant association between statin use and diminished risk of lower extremity amputation, a known complication of DPN. ${ }^{25}$ Further prospective trials including nerve conduction studies have to be performed to establish significant proof in this regard, since only weak evidence has been proposed, and there are still many controversial findings.

There was a reduction in NSS of up to $50 \%$ in both groups; however, neuropathic pain is a subjective parameter described by the patient, and improvement could be due to a subjective perception in response to receiving a therapeutic intervention. We observed an increase in peroneal nerve conduction velocity after 16 weeks of treatment, whereas the NATHAN (Neurological assessment of thioctic acid in diabetic neuropathy) 1 trial (ClinicalTrials.gov identifier NCT00977483 ) was unable to show improvement of nerve conduction studies after 4 years of treatment with alpha-lipoic acid, which is probably explained by the mechanism of action of alpha-lipoic acid with regard to small nerve fibers, which are not measurable by electrodiagnostic studies. ${ }^{26}$ The reason for our findings could be the short-term nature of the trial, and treatment should be extended at least for a year to confirm the ability of rosuvastatin to improve 
Table 3 Nerve conduction studies

\begin{tabular}{|c|c|c|c|c|c|c|}
\hline \multirow[t]{2}{*}{ Nerves } & \multicolumn{2}{|c|}{ Rosuvastatin $(n=17)$} & \multirow[t]{2}{*}{$P$-value } & \multicolumn{2}{|c|}{ Placebo $(n=17)$} & \multirow[t]{2}{*}{$P$-value } \\
\hline & Baseline & Final & & Baseline & Final & \\
\hline \multicolumn{7}{|l|}{ Leg } \\
\hline Amplitude $(\mu \mathrm{V})$ & $14.0 \pm 9.7$ & $15.6 \pm 5.8$ & 0.1 & $19.8 \pm 8.8$ & $19.4 \pm 13.3$ & 0.9 \\
\hline Latency (msec) & $2.9 \pm 0.6$ & $3.0 \pm 0.5$ & 0.6 & $3.1 \pm 0.4$ & $3.3 \pm 0.7$ & 0.7 \\
\hline \multicolumn{7}{|l|}{ Peroneal } \\
\hline Ankle width (mV) & $4.1 \pm 2.2$ & $3.8 \pm 2.1$ & 0.9 & $3.3 \pm 2.1$ & $3.5 \pm 2.3$ & 0.8 \\
\hline Amplitude at fibula (mV) & $3.2 \pm 1.9$ & $4.1 \pm 2.4$ & 0.8 & $3.6 \pm 2.3$ & $4.0 \pm 2.0$ & 0.2 \\
\hline Conduction velocity (m/sec) & $40.8 \pm 2.2$ & $42.1 \pm 1.6$ & 0.03 & $4 I .2 \pm 4.4$ & $41.9 \pm 4.5$ & 0.5 \\
\hline \multicolumn{7}{|l|}{ Tibial } \\
\hline Amplitude ankle (mV) & $5.3 \pm 3.3$ & $6.9 \pm 5.3$ & 0.4 & $7.5 \pm 5.1$ & $8.5 \pm 4.6$ & 0.7 \\
\hline Amplitude in popliteal fossa (mV) & $3.4 \pm 2.4$ & $4.8 \pm 4.4$ & 0.08 & $5.7 \pm 4.8$ & $6.4 \pm 3.9$ & 0.2 \\
\hline Conduction velocity $(\mathrm{m} / \mathrm{sec})$ & $41.8 \pm 5.7$ & $43.1 \pm 5.9$ & 0.5 & $40.4 \pm 4.2$ & $41.0 \pm 4.6$ & 0.2 \\
\hline F-wave latency (msec) & $48.2 \pm 6.5$ & $49.0 \pm 7.7$ & 0.5 & $47.8 \pm 4.9$ & $47.6 \pm 5.4$ & 0.9 \\
\hline \multicolumn{7}{|l|}{ Arm } \\
\hline \multicolumn{7}{|l|}{ Median } \\
\hline Amplitude on wrist $(\mu \mathrm{V})$ & $23.6 \pm 9.2$ & $24.5 \pm 8.5$ & 0.5 & $25.5 \pm 17.3$ & $30.5 \pm 17.7$ & 0.3 \\
\hline Elbow breadth $(\mu \mathrm{V})$ & $14.4 \pm 7.2$ & $12.5 \pm 6.4$ & 0.4 & $16.2 \pm 9.1$ & $16.4 \pm 10.7$ & 0.8 \\
\hline Conduction velocity (m/sec) & $49.3 \pm 5.2$ & $50.1 \pm 4.4$ & 0.08 & $51.2 \pm 4.5$ & $50.4 \pm 7.5$ & 0.6 \\
\hline \multicolumn{7}{|l|}{ Ulnar } \\
\hline Amplitude on wrist (mV) & $8.1 \pm 2.7$ & $8.0 \pm 2.2$ & 0.8 & $8.2 \pm 2.4$ & $8.7 \pm 2.6$ & 0.4 \\
\hline Amplitude below the elbow (mV) & $7.4 \pm 4.2$ & $6.6 \pm 2.2$ & 0.7 & $6.9 \pm 2.5$ & $7.1 \pm 2.7$ & 0.7 \\
\hline Amplitude above the elbow ( $\mathrm{mV}$ ) & $7.2 \pm 5.3$ & $6.6 \pm 1.9$ & 0.5 & $6.7 \pm 2.0$ & $7.0 \pm 2.4$ & 0.6 \\
\hline Amplitude of armpit (mV) & $7.8 \pm 1.6$ & $7.0 \pm 3.3$ & 0.1 & $7.3 \pm 4.1$ & $6.8 \pm 3.0$ & 0.7 \\
\hline Supraclavicular amplitude (mV) & $6.5 \pm 2.5$ & $5.7 \pm 2.0$ & 0.5 & $5.9 \pm 2.6$ & $6.3 \pm 1.7$ & 0.5 \\
\hline Velocity below the wrist $(\mathrm{m} / \mathrm{sec})$ & $48.9 \pm 6.2$ & $51.2 \pm 6.2$ & 0.3 & $49.5 \pm 6.5$ & $50.0 \pm 6.6$ & 0.9 \\
\hline Velocity below and above the elbow $(\mathrm{m} / \mathrm{sec})$ & $50.6 \pm 8.5$ & $48.9 \pm 11.6$ & 0.3 & $50.4 \pm 6.1$ & $50.0 \pm 9.2$ & 0.2 \\
\hline Velocity above the elbow-armpit (m/sec) & $50.4 \pm 2.7$ & $51.6 \pm 7.0$ & 0.5 & $50.8 \pm 6.5$ & $51.9 \pm 6.1$ & 0.5 \\
\hline Supraclavicular velocity axillary fossa $(\mathrm{m} / \mathrm{sec})$ & $54.5 \pm 9.1$ & $53.6 \pm 5.7$ & 0.5 & $52.1 \pm 8.9$ & $51.7 \pm 4.7$ & 0.4 \\
\hline F-wave latency (msec) & $26.5 \pm 1.7$ & $26.3 \pm 2.1$ & 0.9 & $26.9 \pm 3.2$ & $27.0 \pm 3.5$ & 0.7 \\
\hline
\end{tabular}

Notes: There was a significant increase in conduction velocity of the peroneal nerve in the rosuvastatin group and a tendency towards significance in amplitude of the tibial nerve in the popliteal fossa and conduction velocity of the median nerve $(P<0.08)$. There was no significant difference between baseline and final nerve conduction studies in the control group. The bold $P$-value indicates statistical significance.

Table 4 Lipid and hepatic profile

\begin{tabular}{|c|c|c|c|c|c|c|}
\hline & $\begin{array}{l}\text { Rosuvastatin } \\
(n=\mid 7)\end{array}$ & $\begin{array}{l}\text { Placebo } \\
(n=17)\end{array}$ & $P$-value & $\begin{array}{l}\text { Rosuvastatin } \\
(n=17)\end{array}$ & $\begin{array}{l}\text { Placebo } \\
(n=17)\end{array}$ & $P$-value \\
\hline & Baseline & Baseline & & Final & Final & \\
\hline \multicolumn{7}{|l|}{ Lipid profile } \\
\hline Total cholesterol (mg/dL) & $213.1 \pm 49.8$ & $219.1 \pm 25.9$ & 0.5 & $152.2 \pm 36.9$ & $211.7 \pm 26.0$ & 0.001 \\
\hline LDL cholesterol (mg/dL) & $124.4 \pm 44.1$ & $132.1 \pm 26.2$ & 0.5 & $69.1 \pm 28.9$ & $134.7 \pm 29.4$ & 0.001 \\
\hline HDL cholesterol (mg/dL) & $46.6 \pm 10.6$ & $48.4 \pm 8.9$ & 0.4 & $45.8 \pm 11.5$ & $45.3 \pm 8.0$ & 0.8 \\
\hline Triglycerides (mg/dL) & $210.4 \pm 108.5$ & $192.4 \pm 88.7$ & 0.7 & $166.6 \pm 71.3$ & $156.1 \pm 73.8$ & 0.7 \\
\hline \multicolumn{7}{|l|}{ Hepatic profile } \\
\hline GGT (U/L) & $44.2 \pm 29.4$ & $57.4 \pm 44.2$ & 0.2 & $58.7 \pm 70.4$ & $43.4 \pm 35.9$ & 0.5 \\
\hline Total bilirubin (U/L) & $0.6 \pm 0.3$ & $0.6 \pm 0.2$ & 0.9 & $0.7 \pm 0.3$ & $0.7 \pm 0.2$ & 0.6 \\
\hline Direct bilirubin (U/L) & $0.2 \pm 0.2$ & $0.2 \pm 0.1$ & 0.8 & $0.2 \pm 0.1$ & $0.2 \pm 0.1$ & 0.5 \\
\hline Indirect bilirubin $(\mathrm{U} / \mathrm{L})$ & $0.4 \pm 0.2$ & $0.4 \pm 0.2$ & 0.8 & $0.5 \pm 0.2$ & $0.5 \pm 0.2$ & 0.7 \\
\hline Albumin (U/L) & $4.1 \pm 0.3$ & $3.8 \pm 0.3$ & 0.1 & $4.7 \pm 0.6$ & $3.9 \pm 0.4$ & 0.1 \\
\hline ALT (U/L) & $23.4 \pm 8.3$ & $20.9 \pm 9.1$ & 0.4 & $22.7 \pm 7.7$ & $20.6 \pm 9.6$ & 0.4 \\
\hline AST (U/L) & $20.0 \pm 9.2$ & $21.2 \pm 6.1$ & 0.5 & $22.8 \pm 8.9$ & $19.6 \pm 7.6$ & 0.3 \\
\hline Alkaline phosphatase (U/L) & $96.9 \pm 23.9$ & $115.3 \pm 39.4$ & 0.3 & $82.6 \pm 14.2$ & $98.1 \pm 45.6$ & 0.5 \\
\hline
\end{tabular}

Notes: As expected, we found a significant decrease in total cholesterol and low-density lipoprotein cholesterol. There was no significant increase in liver enzymes, which supports the fact that rosuvastatin is a safe drug with few adverse events. The values in bold are statistically significant.

Abbreviations: ALT, alanine transaminase; AST, aspartate transaminase; GGT, gamma-glutamyl transferase; HDL, high-density lipoprotein; LDL, low-density lipoprotein. 
nerve conduction studies; this could also explain the reason that only one nerve was modified. The main disadvantage of alpha-lipoic acid is that it needs to be administered intravenously for the first 3 weeks to achieve the desired effect, whereas rosuvastatin can be administered orally once a day. ${ }^{27,28}$

We observed an improvement in DPN stage for patients on rosuvastatin, which could be partially explained by an increase in the velocity of nerve conduction, lipidic control and decreased lipid peroxidation; determined in the rosuvasatin group, although most studies do not report DPN stage as an outcome. The SYDNEY (Symptomatic diabetic polyneuropathy study) 2 trial (ClinicalTrials.gov identifier NCT00328601) reported improvement in symptoms and NIS after 5 weeks of treatment, but we did not find any such clinical benefit with rosuvastatin, despite the ability of statins to reduce oxidative stress. ${ }^{29}$ Statins reduce production of LPO and reactive oxygen species by increasing the bioavailability of nitric oxide. ${ }^{30}$ Oxidative stress is involved in progression of the microvascular complications of DM; thus, by reducing LPO, a clinical benefit could be expected. Experimental studies in animals suggest that the pleiotropic effects of statins could be mediated by neuronal nitric oxide synthase and signaling via the phosphatidylinositol 3-kinase/Akt pathway. The final outcome may restore microcirculation. ${ }^{31,32}$ Quantification of LPO represents an objective way of measuring oxidative stress, ${ }^{33}$ and a significant reduction was observed in the rosuvastatin group in our study. These findings could be related to improvement of DPN stage, but further studies must be done to demonstrate a correlation between LPO and clinical findings, since our sample size was too small to meet this objective. Intolerance of statin treatment could be explained in part by myopathy and increased transaminases. ${ }^{34}$ Adding calcium blockers or fibrates increases the risk of this side effect; ${ }^{35}$ however, we did not find evidence that neuropathy was made worse by statins.

There was no significant change in $\beta$-NGF levels in either group, indicating that rosuvastatin is not effective for modification of neurotropic factors, at least with the doses and duration of treatment used by our study group. One of the variables influencing nerve function is glycemic control, probably glycemic deregulation affected the final results.

Rosuvastatin proved to be safe, as shown by many other clinical trials, and its pleiotropic effects are apparently unrelated to reduction of lipid levels. ${ }^{36}$ There were few adverse effects and there was no clinical modification on hepatic parameters.
Clinical trials with antioxidants in patients with DPN are limited, and there is not enough evidence to recommend routine use of these agents; however, rosuvastatin showed an ability to reduce oxidative stress, probably by both its lipid-lowering effect leading to amelioration of oxidized lowdensity lipoprotein and its pleiotropic effects independent of lipid levels. ${ }^{37}$ This ability appears to improve DPN staging by modification of nerve conduction study parameters, mostly with regard to peroneal nerve function. Further studies are required, given our small study population size and the fact that our study patients were treated for only 12 weeks. Our study has some limitations, including its small sample size, the heterogeneity of the antidiabetic agents used, poor glycemic control at baseline, and a short period of intervention. However, our findings suggest that rosuvastatin could benefit patients with DM by reducing the progression of microvascular complications, such as DPN.

\section{Disclosure}

The authors report no conflicts of interest in this work.

\section{References}

1. World Health Organisation. Diabetes Programme. Geneva, Switzerland: World Health Organisation; 2012. Available from: http://www.who.int/ diabetes/en/. Accessed June 26, 2014.

2. Jang JE, Kim YT, Park BK, Cheong IY, Kim DH. Subclinical ulnar neuropathy at the elbow in diabetic patients. Ann Rehabil Med. 2014;38:64-71.

3. Ko SH, Cha BY. Diabetic peripheral neuropathy in type 2 diabetes mellitus in Korea. Diabetes Metab J. 2012;36:6-12.

4. Zorrilla E, Frati A, Lozano O, Villalpando S, Boulton AJM. Neuropatía diabética. Conceptos actuales sobre etiopatogénesis, diagnóstico y tratamiento [Diabetic neuropathy. Current concepts on etiopathogenesis, diagnosis, and treatment]. Gac Med Mex. 1994;130:18-25. Spanish.

5. Dyck PJ. Detection, characterization and staging of polyneuropathy: assessed in diabetics. Muscle Nerve. 1988;11:21-32.

6. Bril V, Werb MR, Greene DA, Sima AA. Single-fiber electromyography in diabetic peripheral polyneuropathy. Muscle Nerve. 1996;19:2-9.

7. Dumitru D. Electrodiagnostic Medicine. 2nd ed. Philidelphia, PA, USA: Hanley and Belfus; 2000.

8. Duckworth W. Hyperglycemia and cardiovascular disease. Curr Atheroscler Rep. 2001;3:383-391.

9. Bashan N, Kovsan J, Kachko I, Ovadia H, Rudich A. Positive and negative regulation of insulin signaling by reactive oxygen and nitrogen species. Physiol Rev. 2009;89:27-71.

10. Sima AA. Structure-function interactions in the therapeutic response of diabetic neuropathy. J Diabetes Complications. 1992;6:64-68.

11. Dyck PJ, Giannini C. Pathologic alterations in the diabetic neuropathies of humans: a review. J Neuropathol Exp Neurol. 1996;55:1181-1193.

12. Brownlee M. Biochemistry and molecular cell biology of diabetic complications. Nature. 2001;414:813-820.

13. Zatalia SR, Sanusi H. The role of antioxidants in the pathophysiology, complications, and management of diabetes mellitus. Acta Med Indones. 2013;45:141-147.

14. Clapés S, Torres O, Companioni M, et al. Peroxidación lipídica y otros indicadores de estrés oxidativo en pacientes diabéticos [Lipid peroxidation and other oxidative stress markers in diabetic patients]. Rev Cubana Invest Biomed. 2001;20:93-98. Spanish. 
15. Margaritis M, Channon KM, Antoniades C. Statins as regulators of redox state in the vascular endothelium: beyond lipid lowering. Antioxid Redox Signal. 2014;20:1198-1215.

16. Gazzerro P, Proto MC, Gangemi G, et al. Pharmacological actions of statins: a critical appraisal in the management of cancer. Pharmacol Rev. 2011;64:102-106.

17. Fenster BE, Tsao PS, Rockson SG. Endothelial dysfunction clinical strategies for treating oxidant stress. Am Heart J. 2003;146:218-226.

18. Mennickent CS, Bravo DM, Calvo MC, Avello LM. [Pleiotropic effects of statins]. Rev Med Chil. 2008;136:775-782. Spanish.

19. Giroux LM, Davignon J, Naruszewicz M. Simvastatin inhibits the oxidation of low-density lipoproteins by activated human monocytederived macrophages. Biochim Biophys Acta. 1993;1165:335-338.

20. Parson HK, Bundy MA, Dublin CB, Boyd AL, Paulson JF, Vinik AI. Pleiotropic effects of rosuvastatin on microvascular function in type 2 diabetes. Diabetes Metab Syndr Obes. 2010;3:19-26.

21. England JD, Gronseth GS, Franklin G, et al. Distal symmetric polyneuropathy: a definition for clinical research: report of the American Academy of Neurology, the American Association of Electrodiagnostic Medicine, and the American Academy of Physical Medicine and Rehabilitation. Neurology. 2005;64:199-207.

22. Tesfaye S, Boulton A, Dyck P, et al. Diabetic neuropathies: update on definitions, diagnostic criteria, estimation of severity and treatments. Diabetes Care. 2010;33:2285-2293.

23. Tierney EF, Thurman DJ, Beckles GL, Cadwell BL. Association of statin use with peripheral neuropathy in the US population 40 years of age or older. J Diabetes. 2013;5:207-215.

24. West B, Williams CM, Jilbert E, James AM, Haines TP. Statin use and peripheral sensory perception: a pilot study. Somatosens Mot Res. 2014;31:57-61.

25. Sohn MW, Meadows JL, Oh EH, et al. Statin use and lower extremity amputation risk in nonelderly diabetic patients. J Vasc Surg. 2013;58:1578-1585.

26. McIlduff CE, Rutkove SB. Critical appraisal of the use of alpha lipoic acid (thioctic acid) in the treatment of symptomatic diabetic polyneuropathy. Ther Clin Risk Manag. 2011;7:377-385.
27. Poh ZX, Goh KP. A current update on the use of alpha lipoic acid in the management of type 2 diabetes mellitus. Endocr Metab Immune Disord Drug Targets. 2009;9:392-398.

28. Golbidi S, Badran M, Laher I. Diabetes and alpha lipoic acid. Front Pharmacol. 2011;2:69-72.

29. Ziegler D, Ametov A, Barinov A, et al. Oral treatment with $\alpha$-lipoic acid improves symptomatic diabetic polyneuropathy. SYDNEY 2 trial. Diabetes Care. 2006;29:2365-2370.

30. Wassmann S, Laufs U, Baumer AT, et al. HMG-CoA reductase inhibitors improve endothelial dysfunction in normocholesterolemic hypertension via reduced production of reactive oxygen species. Hypertension. 2001;37:1450-1457.

31. Li M, Nishimura H, Kusano KF, et al. Neuronal nitric oxide synthase mediates statin-induced restoration of vasa nervorum and reversal of diabetic neuropathy. Circulation. 2005;112:93-102.

32. Fujii T, Onimaru M, Yonemitsu Y, Kuwano H, Sueishi K. Statins restore ischemic limb blood flow in diabetic microangiopathy via eNOS/NO upregulation but not via PDGF-BB expression. Am J Physiol Heart Circ Physiol. 2008;294:H2785-H2791.

33. Thomas PK. Classification, differential diagnosis, and staging of diabetic peripheral neuropathy. Diabetes. 1997;46:54-57.

34. Arca M, Pigna G. Treating statin-intolerant patients. Diabetes Metab Syndr Obes. 2011;4:155-166.

35. Settergren J, Eiermann B, Mannheimer B. Adherence to drug label recommendations for avoiding drug interactions causing statin-induced myopathy - a nationwide register study. PLoS One. 2013;8:e69545.

36. Shishehbor MH, Brennam ML, Aviles RJ, et al. Statins promote potent systemic antioxidants effects through specific inflammatory pathways. Circulation. 2003;108:426-431.

37. Abe M, Maruyama N, Okada K, Matsumoto S, Matsumoto K, Soma M. Effects of lipid-lowering therapy with rosuvastatin on kidney function and oxidative stress in patients with diabetic nephropathy. $J$ Atheroscler Thromb. 2011;18:1018-1028.

\section{Publish your work in this journal}

Diabetes, Metabolic Syndrome and Obesity: Targets and Therapy is an international, peer-reviewed open-access journal committed to the rapid publication of the latest laboratory and clinical findings in the fields of diabetes, metabolic syndrome and obesity research. Original research, review, case reports, hypothesis formation, expert opinion and commentaries are all considered for publication. The manuscript management system is completely online and includes a very quick and fair peer-review system, which is all easy to use. Visit http://www.dovepress.com/testimonials.php to read real quotes from published authors. 